\title{
An oral regimen of cyproterone acetate and testosterone undecanoate for spermatogenic suppression in men
}

\author{
M. Cristina Meriggiola, M.D.* \\ Anna Pavani, Ph.D. \\ William J. Bremner, M.D. $\dagger$ \\ Maurizio Capelli, Ph.D. $\ddagger$ \\ Antonietta Costantino, Ph.D.* \\ Carlo Flamigni, M.D.*
}

\begin{abstract}
Department of Obstetrics and Gynecology, Reproductive Medicine Unit and Core Lab, S. Orsola Hospital, University of Bologna, Bologna, Italy, and Department of Veterans Affairs Puget Sound Health Care System, Population Center for Research in Reproduction, University of Washington School of Medicine, Seattle, Washington
\end{abstract}

Objective: To test the effectiveness, safety, and reversibility of the combined administration of cyproterone acetate and $\mathrm{T}$ undecanoate.

Design: Open clinical trial.

Setting: Healthy volunteers in an academic research environment.

Patient(s): Eight healthy men, aged 25-42 years were selected.

Intervention(s): Cyproterone acetate, $12.5 \mathrm{mg}$, and T undecanoate, $80 \mathrm{mg}$, were administered orally twice daily for 16 weeks.

Main Outcome Measure(s): Semen analyses every 2 weeks; physical examination, chemistries, hematology, prostatic-specific antigen, gonadotropins and $\mathrm{T}$ levels, and a questionnaire on sexual and behavioral function every 4 weeks.

Result(s): In all subjects a profound suppression of spermatogenesis occurred; one subject became azoospermic, five subjects had sperm counts of $\leq 3 \times 10^{6} / \mathrm{mL}$, and in two subjects sperm counts were 4 and $6 \times 10^{6} \mathrm{~mL}$ in week 16 . Sperm counts returned to baseline in all men after hormone administration was discontinued. No changes in metabolic parameters and total prostatic-specific antigen were detected. Hemoglobin and hematocrit decreased statistically significantly at week 16 of treatment and returned to baseline by week 12 of recovery. There was no change in sexual function or behavior.

Conclusion(s): The oral administration of $\mathbf{T}$ undecanoate plus cyproterone acetate induces a profound suppression of spermatogenesis with no major adverse effects. These data suggest the feasibility of oral contraception in men. (Fertil Steril ${ }^{\circledR 1} 1997 ; 68: 844-50$. (C) 1997 by American Society for Reproductive Medicine.)

Key Words: Cyproterone acetate, $\mathrm{T}$ undecanoate, spermatogenesis, gonadotropins

Almost all trials of male contraception have used weekly or biweekly intramuscular injections of testosterone preparations to maintain $\mathrm{T}$ levels within

Received February 24, 1997; revised and accepted July 21, 1997.

This work was supported by the Department of Obstetrics and Gynecology, S. Orsola Hospital, Bologna, Italy and by the Andrew W. Mellon Foundation, New York, New York 10021 (in association with the University of Washington Population Center for Research in Reproduction).

Presented at The International Congress of Endocrinology held in San Francisco, June 14-15, 1996.

Reprint requests: M. Cristina Meriggiola, M.D., Department of Obstetrics and Gynecology and Reproductive Medicine Unit, S. Orsola Hospital, Via Massarenti 13, 40138 Bologna, Italy (FAX: 51-304661; E-MAIL: crismeri@tin.it). the physiological range (1). These $\mathrm{T}$ formulations are not acceptable for long-term contraception by the population at large. Oral preparations or long-acting (3-4 months) injections would be much more acceptable techniques $(2,3)$. Oral regimens are preferred over long-acting formulations by some men because they provide more personal control, allowing users to stop when they want to and do not require any kind of painful procedure sometimes

\footnotetext{
* Department of Obstetrics and Gynecology, Reproductive Medicine Unit, S. Orsola Hospital.

$\uparrow$ Department of Veterans Affairs, Puget Sound Health Care System.

$\ddagger$ Core Lab, S. Orsola Hospital.
} 
necessary to insert long-acting delivery systems. Not much effort has been put into the development of oral contraceptive regimens for men. One of the reasons is the lack of optimal oral androgen formulations.

The development of oral $\mathrm{T}$ preparations has been hampered by the fact that, when administered orally, $\mathrm{T}$ is inactivated quickly by the liver. The alkylation of $T$ at the 17 position has led to molecules that are more resistant to hepatic breakdown but are also hepatotoxic (4). The only suitable oral $\mathrm{T}$ preparation available thus far is $\mathrm{T}$ undecanoate.

Because of its lipophilic properties due to the long aliphatic side chain, $\mathrm{T}$ undecanoate is absorbed through the intestinal lymphatic vessels and enters the systemic circulation through the thoracic vein, thus escaping immediate inactivation by the liver $(5,6)$. T undecanoate does not have a 17-alkyl group and therefore avoids problems with liver toxicity. Because of these characteristics, $T$ undecanoate has been used for many years as long-term replacement therapy in hypogonadal men (7). Long-term studies, up to 10 years, have shown that this oral androgen is safe (7).

In this study we decided to test potential effectiveness, safety, acceptability, and practicality of an oral contraceptive for men. Regimens based on the combined administration of two steroids (a progestin and an androgen) very effectively suppress spermatogenesis and, at the same time, allow maintenance of androgen levels within the physiologic range, therefore avoiding androgen-related side effects $(8,9)$. In this study we administered cyproterone acetate and $\mathrm{T}$ undecanoate orally.

Recently, we reported that the administration of cyproterone acetate at a dose of $25 \mathrm{mg} / \mathrm{d}$ in combination with $100 \mathrm{mg} / \mathrm{wk}$ of $\mathrm{T}$ enanthate induces a profound suppression of spermatogenesis in all tested subjects (10). Therefore, in this study we combined cyproterone acetate, $25 \mathrm{mg} /$ day, with $\mathrm{T}$ undecanoate at a dose of $160 \mathrm{mg} /$ day, which is the dose that has been reported to provide effective replacement therapy in hypogonadal subjects.

\section{MATERIALS AND METHODS}

\section{Subjects}

Eight normal white men, aged 25-42 years $(30 \pm 3$ years; mean $\pm \mathrm{SE})$ were enrolled in this study. All men were healthy by medical history, physical examination, and screening laboratory tests. All men had basal sperm counts of $>20 \times$ $10^{6} / \mathrm{mL}$ as well as gonadotropin and T levels within the normal range. The Internal Review Board of the
Clinic of Obstetrics and Gynecology, S. Orsola Hospital approved the study, and each man signed an informed consent form.

\section{Clinical Protocol}

The study included a control period lasting at least 6 weeks, a 16-week treatment period, and a recovery period that lasted until subjects had at least two sperm counts within their own baseline range. During the control phase, subjects were asked to provide three seminal fluid samples separated from each other by at least 7 days and three fasting blood samples separated by at least 1 week and to complete three sexual and behavioral questionnaires separated by at least 2 weeks.

During the treatment phase, the subjects provided seminal fluids every 2 weeks and fasting (at least 10 hours) blood samples every 4 weeks. In five men, on week 12 of hormone administration, blood samples were drawn hourly for 12 hours. Samples were stored at $-20^{\circ} \mathrm{C}$ until assayed. Every 4 weeks, volunteers attended the clinic to undergo physical examination and weighing. During these visits, volunteers also were asked to complete a sexual and behavioral questionnaire. Throughout the study periods, subjects were asked to abstain from sexual intercourse for 3 to 7 days, as dictated by World Health Organization guidelines (11).

Subjects were asked to take T undecanoate, $80 \mathrm{mg}$ twice a day orally, plus cyproterone acetate, $12.5 \mathrm{mg}$ twice a day orally. Subjects were asked to take pills 12 hours apart, with food. A special diet was not required.

Testosterone undecanoate (Andriol; Organon, Rome, Italy) formulated in arachidonic oil and cyproterone acetate (Androcur; Schering, Milan, Italy) were taken orally.

\section{Measurements}

Semen samples were analyzed according to the World Health Organization laboratory manual (11, 12). Azoospermia was defined as no sperm found in a sample after centrifugation and analysis of the pellet. Severe oligozoospermia was defined as a sperm count of $\leq 3 \times 10^{6} / \mathrm{mL}$. Recovery of sperm count was calculated considering the first of at least two sperm counts within the baseline range of each subject. Testis size was estimated with use of Prader's orchiometer. Luteinizing hormone, FSH, and T were measured according to previously described methodologies (13). Hematology (hemoglobin [Hb], hematocrit [Hct], and red blood cells), chemistry (total cholesterol, high-density lipoprotein (HDL) cholesterol, triglycerides, low-density lipoprotein (LDL) 


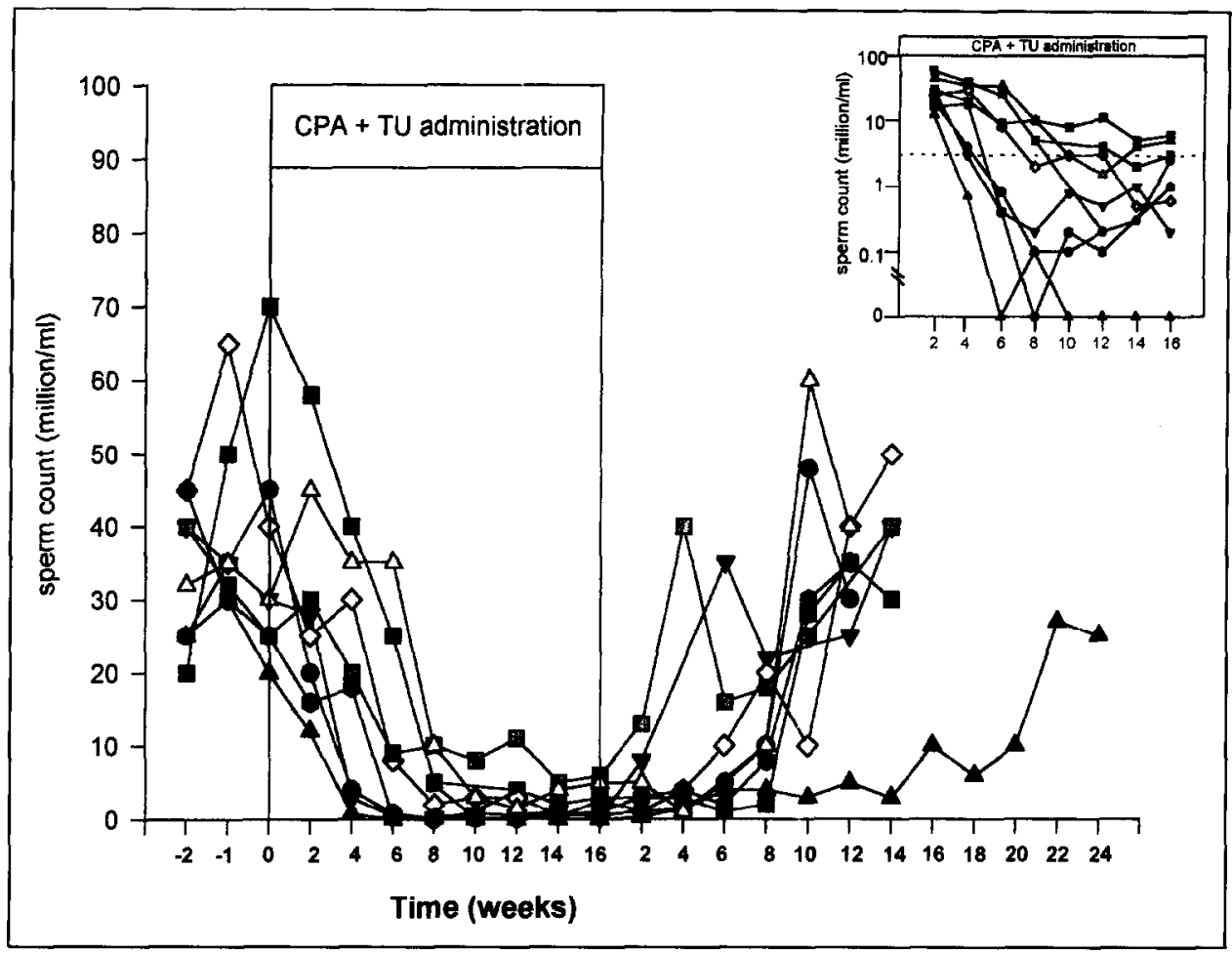

Figure 1 Individual sperm concentration throughout the study periods (control, weeks $-2,-1$, and 0 ; treatment, 16 weeks; and recovery, 24 weeks). The inset shows in greater details sperm concentration during hormone administration ( $\log$ scale). In the inset, the sperm count threshold of $3 \times 10^{6} / \mathrm{mL}$ is indicated by the dashed line (21).

cholesterol, urea, creatinine, glutamic oxaloacetic transaminase (GOT), glutamate-pyruvate transaminase (GPT), and total bilirubin), and electrolytes (sodium, potassium, calcium, and phosphorus) were also measured according to previously validated methodologies (13). Serum prostatic specific antigen (PSA) concentrations were measured by an immunoenzymatic assay (PSA kit, AIA-PACK; Eurogenetics, Tosoh Co., Japan) (14). The minimum sensitivity of this assay is $0.1 \mathrm{ng} / \mathrm{mL}$. The intraassay and interassay coefficients of variation (CV) at low, medium, and high levels of the standard curve were $2.9 \%, 3.9 \%$, and $3.0 \%$ and $2.1 \%, 3.9 \%$, and $2.8 \%$, respectively.

\section{Statistics}

Multifactorial analysis of variance (ANOVA) with repeated measures and $t$-test were used to determine differences within each treatment group across time and between study groups of any parameter. Sperm count data were log-transformed before analysis (12).

\section{RESULTS}

\section{Semen Parameters}

The mean $( \pm \mathrm{SE})$ baseline sperm concentration was $36.2 \pm 2.6 \times 10^{6} / \mathrm{mL}$. Six of the eight men became azoospermic or severely oligozoospermic (Fig. 1). Among them, one man was azoospermic on week
10 and remained azoospermic until the end of hormone administration (week 16). Five men had sperm counts of $0.1,0.6,1,2.5$, and $3 \times 10^{6} / \mathrm{mL}$ on week 16. Sperm counts of the other two men were 5 and $6 \times 10^{6} / \mathrm{mL}$ on week 16 . Time to achieve severe oligozoospermia in the five men that became severely oligozoospermic and in the man that eventually became azoospermic was $8.0 \pm 1.5$ weeks. After stopping hormone administration, sperm counts returned to baseline levels in all men. Mean time to return to baseline was $11.3 \pm 1.6$ weeks (range, 6-22 weeks).

\section{Hormone Levels}

Luteinizine, hormone, FSH, and T levels at baseline were $3.4 \pm 0.4 \mathrm{IU} / \mathrm{L}, 2.2 \pm 0.2 \mathrm{IU} / \mathrm{L}$, and 17.1 $\pm 0.7 \mathrm{nmol} / \mathrm{L}$ (mean $\pm \mathrm{SE}$ ), respectively. By week 4 of hormone administration $\mathrm{LH}$ and FSH serum levels showed a statistically significant decrease in all men (Fig. 2). At week 16, both LH and FSH were significantly higher than at week 4 of hormone administration $(P<0.05)$. A great variability in hormone levels was found in monthly blood samples. This variability is likely due in large part to the fact that these samples were taken at different times after the daily intake of the pills.

In frequent sampling studies performed at week 12 , T peaked in blood at $3.0 \pm 0.3$ hours $(2-4$ hours) after $\mathrm{T}$ undecanoate intake and remained above 
baseline for at least 6 hours (Fig. 3). Peak T levels were $43.3 \pm 14.9 \mathrm{nmol} / \mathrm{L}$ (range, $13.8-96.4 \mathrm{nmol} / \mathrm{L}$ ). The daily pattern of gonadotropin at week 12 is shown in Figure 3, top and middle panels. Levels of both gonadotropins and $T$ returned to baseline by week 4 of the recovery phase.

\section{Lipids, Blood Chemistry, Electrolytes, and Hematology}

Metabolic tests, electrolytes, and lipoprotein plasma levels did not show any statistically significant change in any phase of the study. A statistically significant reduction of $\mathrm{Hb}$ and $\mathrm{Hct}$ was present at week 16 of hormone administration (Table 1). By week 12 of recovery, all hematologic parameters had returned to baseline values.

\section{Clinical}

Testicular size decreased in all subjects after hormone administration. Mean baseline testis volumes were $20.4 \pm 0.4$ and $19.8 \pm 0.45 \mathrm{~mL}$ for the right and left testis, respectively. At week 16 of hormone administration testis volumes were $14 \pm 1 \mathrm{~mL}$ in both testes (decrease was $31 \% \pm 3 \%$; mean $\pm \mathrm{SE}$ ). Testis size returned to normal in all subjects after hormone administration was discontinued. No change of body weight was registered in any subject. Three subjects reported occurrence of occasional diarrhea that disappeared after termination of hormone intake. No change in serum concentrations of total PSA was detected in any phase of the study (baseline, $0.6 \pm 0.1 \mathrm{ng} / \mathrm{mL}$; week $16,0.5 \pm 0.2 \mathrm{ng}$ / $\mathrm{mL}$; recovery week $12,0.8 \pm 0.2 \mathrm{ng} / \mathrm{mL}$ ).

No changes in frequency of sexual intercourse, desires, fantasies, masturbation, kissing, and measures of aggressive behavior and mood states were reported.

\section{DISCUSSION}

In this study we tested the effectiveness of an oral hormonal contraceptive regimen consisting of the combined administration of cyproterone acetate and $T$ undecanoate. To our knowledge, this is the first study to evaluate the effects of a combined oral contraceptive for men. This regimen was very well received by all the men, and it was considered practical and suitable for long-term use by all of them. With the dose of cyproterone acetate and $T$ undecanoate that we tested in this study, spermatogenesis decreased in all the men, but azoospermia or severe oligozoospermia was achieved in only six of eight.

Suppression of gonadotropins was extremely vari-

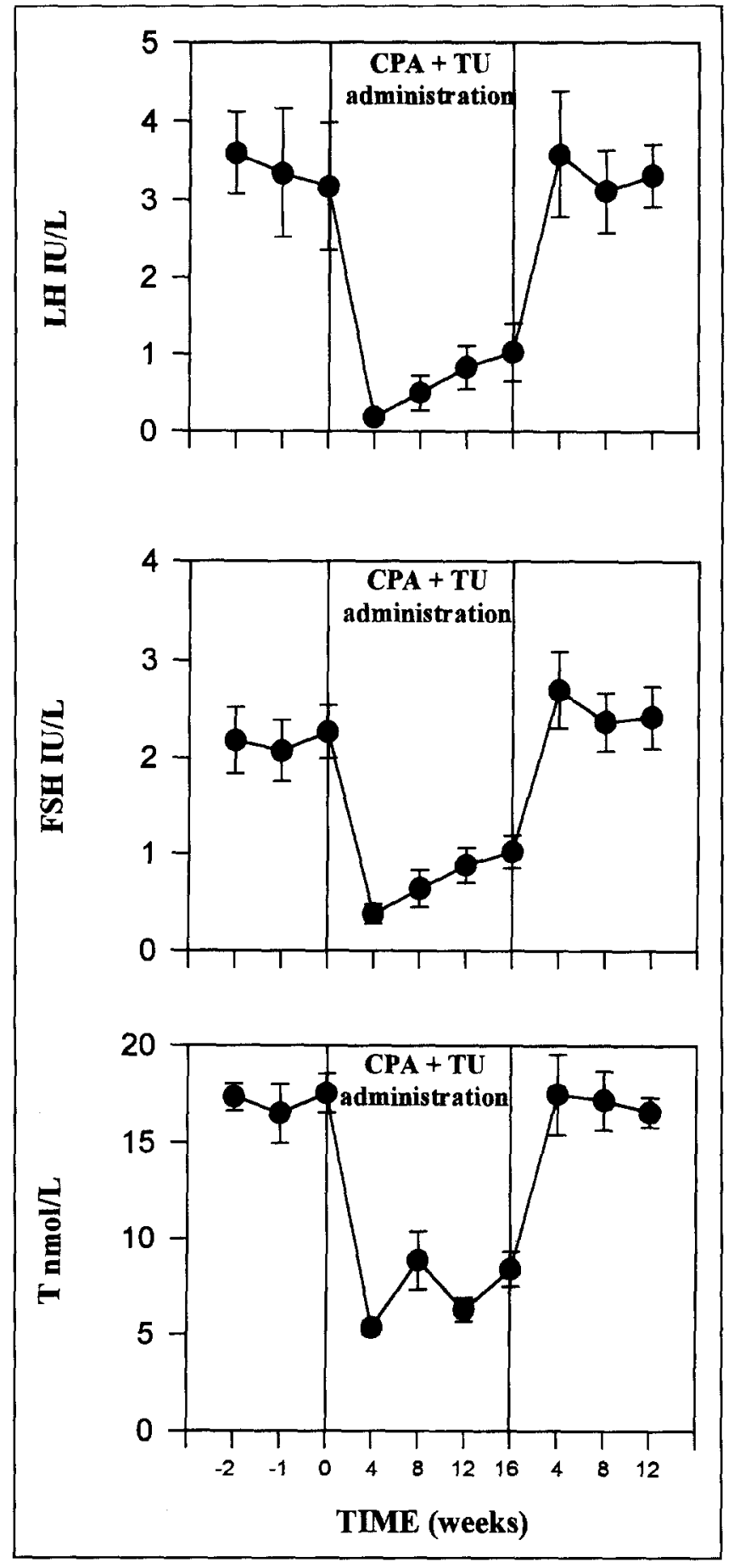

Figure 2 Mean ( $\pm \mathrm{SE}$ ) serum LH (top), FSH (middle), and T (bottom) levels before starting hormone administration, every 4 weeks throughout hormone administration and every 4 weeks for 12 weeks after stopping hormone administration.

able from one man to the next and in the same man at different times. A great between- and within-subject variability in $T$ serum levels also was found, attributable to rapid clearance of the androgen and variable sampling times.

Previous studies showed that the administration 


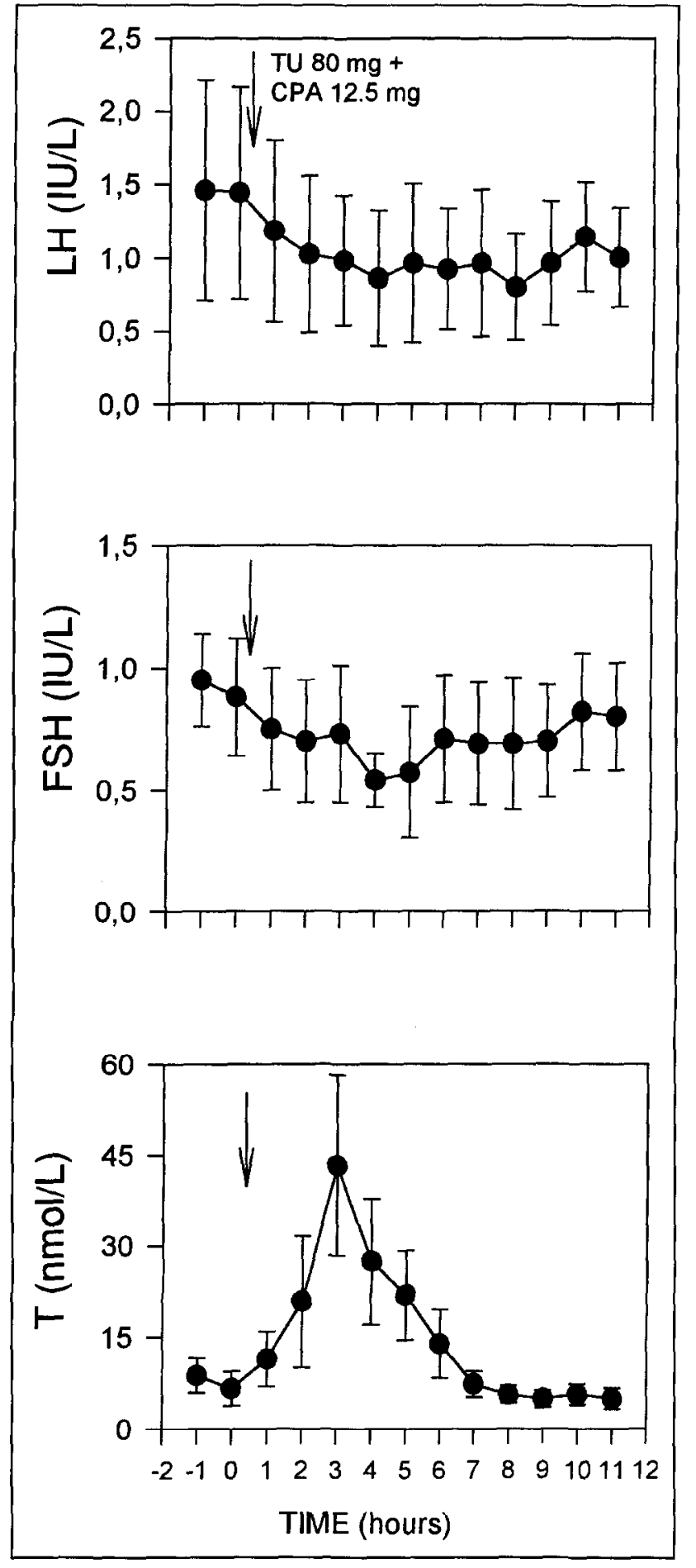

Figure 3 Mean ( $\pm \mathrm{SE}$ ) serum LH (top), FSH (middle), and T (bottom) levels in five subjects hourly for 11 hours after administration of $\mathrm{T}$ undecanoate, $80 \mathrm{mg}$, plus cyproterone acetate, 12.5 $\mathrm{mg}$, at week 12 of the study.

of the progestin/antiandrogen cyproterone acetate in combination with an injectable formulation of $\mathrm{T}$ enanthate represents a promising male contraceptive regimen $(10,13,15,16)$. The rationale for adding cyproterone acetate to $\mathrm{T}$ enanthate is based on the hypothesis that the synergistic action of these compounds can induce a more profound suppression of gonadotropins than either compound administered alone and that cyproterone acetate can act directly at the gonadal level to block the stimulatory effects of androgens on spermatogenesis.

Cyproterone acetate administered at the same dose that we used in this study ( $25 \mathrm{mg} / \mathrm{d}$ ) combined with weekly administration of $100 \mathrm{mg}$ of $\mathrm{T}$ enanthate induced azoospermia or near-azoospermia in all men (10). It is most likely that the difference in sperm suppression between this and our previous study is attributable to the more limited ability of $T$ undecanoate to suppress gonadotropin secretion when compared with $\mathrm{T}$ enanthate $(17,18)$. Similarly the administration of $\mathrm{T}$ undecanoate, alone or in combination with GnRH agonists, to normal men for male contraception, induced only a poor suppression of gonadotropins $(17,18)$.

Both LH and FSH levels were statistically significantly higher in week 16 than in week 4 of hormone administration. It is not clear whether this difference may be attributable to a decrease of the subjects' compliance to the regimen or whether a progressive escape from suppression may have occurred.

In this study, only six of the eight subjects became azoospermic or severely oligozoospermic, whereas in the other two subjects sperm count was greatly reduced but did not drop below $3 \times 10^{6} / \mathrm{mL}$. In previous studies it was shown that azoospermia or severe oligozoospermia induced by $200 \mathrm{mg} / \mathrm{wk}$ of $\mathrm{T}$ enanthate resulted in a low contraceptive failure rate $(20,21)$. Consequently, it is generally agreed that the

Table 1 Laboratory Tests Throughout the Study Period

\begin{tabular}{|c|c|c|c|}
\hline \multirow[b]{2}{*}{ Laboratory test } & \multicolumn{3}{|c|}{$\mathrm{TU}$ (160 mg/day) + CPA (25 mg/day) } \\
\hline & Baseline & Weok 16 & Recovery \\
\hline $\begin{array}{l}\text { Total cholesterol }(\mathrm{mmol} / \mathrm{L}) \\
\text { HDL cholesterol }(\mathrm{mmol} / \mathrm{L}) \\
\text { Tryglyceride }(\mathrm{mmol} / \mathrm{L}) \\
\text { LDL cholesterol }(\mathrm{mmol} / \mathrm{L})\end{array}$ & $\begin{array}{l}5.1 \pm 0.3 \\
1.3 \pm 0.07 \\
3.0 \pm 0.3 \\
3.2 \pm 0.2\end{array}$ & $\begin{array}{l}4.7 \pm 0.3 \\
1.2 \pm 0.07 \\
2.4 \pm 0.3 \\
3.1 \pm 0.3\end{array}$ & $\begin{array}{l}5.2 \pm 0.4 \\
1.3 \pm 0.07 \\
2.4 \pm 0.3 \\
3.4 \pm 0.4\end{array}$ \\
\hline $\begin{array}{l}\text { GOT }(\mathrm{U} / \mathrm{L}) \\
\text { GPT }(\mathrm{U} / \mathrm{L}) \\
\text { Total bilirubin }(\mu \mathrm{mol} / \mathrm{L}) \\
\text { Urea }(\mathrm{mmol} / \mathrm{L}) \\
\text { Creatinine }(\mu \mathrm{mol} / \mathrm{L})\end{array}$ & $\begin{aligned} 22 & \pm 1 \\
25 & \pm 4 \\
13.7 & \pm 1.4 \\
5.7 & \pm 0.2 \\
98 & \pm 2\end{aligned}$ & $\begin{aligned} 19 & \pm 1 \\
19 & \pm 3 \\
13.0 & \pm 1.4 \\
5.2 & \pm 0.5 \\
96 & \pm 2\end{aligned}$ & $\begin{aligned} 22 & \pm 1 \\
26 & \pm 5 \\
12.1 & \pm 1.9 \\
5.3 & \pm 0.5 \\
94 & \pm 2\end{aligned}$ \\
\hline $\begin{array}{l}\text { Sodium }(\mathrm{mmol} / \mathrm{L}) \\
\text { Potassium }(\mathrm{mmol} / \mathrm{L}) \\
\text { Calcium }(\mathrm{mmol} / \mathrm{L}) \\
\text { Phosphorus }(\mathrm{mmol} / \mathrm{L})\end{array}$ & $\begin{aligned} 144 & \pm 1 \\
4.9 & \pm 0.1 \\
2.5 & \pm 0.03 \\
3.3 & \pm 0.1\end{aligned}$ & $\begin{aligned} 145 & \pm 1 \\
4.6 & \pm 0.1 \\
2.5 & \pm 0.04 \\
4.0 & \pm 0.2\end{aligned}$ & $\begin{aligned} 143 & \pm 2 \\
4.6 & \pm 0.2 \\
2.5 & \pm 0.04 \\
3.5 & \pm 0.2\end{aligned}$ \\
\hline $\begin{array}{l}\operatorname{Hb}(g / L) \\
\operatorname{Hct}(\%) \\
\operatorname{RBCs}\left(\times 10^{6} / L\right)\end{array}$ & $\begin{aligned} 153 & \pm 2 \\
46 & \pm 1 \\
5.6 & \pm 0.2\end{aligned}$ & $\begin{aligned} 143 & \pm 5^{*} \\
42 & \pm 1^{*} \\
5.1 & \pm 0.2\end{aligned}$ & $\begin{array}{r}151 \pm 4 \\
45 \pm 1 \\
5.4 \pm 2\end{array}$ \\
\hline
\end{tabular}

* Significantly different $(P<0.05)$ from baseline. 
achievement of azoospermia or at least severe oligozoospermia in all subjects must be a mandatory goal of any male hormonal contraceptive regimen. Therefore, the next step in the development of an oral contraceptive regimen for men will be to adjust the doses of the progestin or of the androgen to achieve a more profound suppression of spermatogenesis.

No significant change in any biochemical parameters and electrolytes could be detected throughout the study period. No change in body weight was reported, but testis volume decreased in all subjects. This regimen did not cause changes in total PSA serum levels. In agreement with our previous studies in which we administered cyproterone acetate in combination with $\mathrm{T}$ enanthate to healthy men (13), there was a statistically significant decrease of $\mathrm{Hb}$ and Hct after 16 weeks of cyproterone acetate plus $\mathrm{T}$ undecanoate administration.

Although inconsistent, a decrease of hematologic parameters after cyproterone acetate administration has been reported before both in men (13) and in women (22). This effect could be attributable to either a direct action of this compound on the hematologic system or, more likely, to the antiandrogenic property of cyproterone acetate. Indeed, although in this study we did not observe any metabolic effect, over a long period of administration the fluctuating $T$ levels to which men are exposed after $T$ undecanoate intake could also have negative effects on the other androgen-dependent physiologic functions such as bone metabolism, muscle strength, and some aspects of sexual function.

Most of the research on hormonal male contraception performed thus far has been aimed at developing long-acting regimens (2). Little effort has been put into testing oral regimens. One of the reasons is the lack of a suitable oral androgen preparation. Although widely used in replacement therapy for hypogonadal men, $T$ undecanoate is far from being an optimal androgen to be used in male contraceptive regimens for two main reasons: [1] it does not provide a good suppression of gonadotropins and [2] fluctuating $T$ levels that follow its administration might have negative metabolic effects.

We believe that giving men the option of both oral and long-acting contraceptive formulations would improve greatly the overall acceptability of and level of compliance with contraceptive regimens. Results of our study suggest that an effective combined oral male contraceptive regimen can indeed be developed, but they also show that the development of a more suitable androgen preparation is mandatory to achieve this goal.

In conclusion, results of our study demonstrate that the combined oral administration of $\mathrm{T}$ un- decanoate with cyproterone acetate induces a profound suppression of sperm production in normal men without causing major side effects. These results suggest that oral contraception for men is feasible. Further studies aimed at developing new oral androgens with more favorable biological properties and at adjusting the dose of both the androgen and the progestin to obtain a more profound sperm suppression promise to lead to an effective and acceptable oral contraceptive for men.

Acknowledgment. The authors gratefully acknowledge the help of Liza Noonan, B.S., WHI Clinical Coordinating Center, Fred Hutchinson Cancer Center, for performing the statistical analysis.

\section{REFERENCES}

1. Cummings DE, Bremner WJ. Prospects for new hormonal male contraceptives. Clin Endocrinol Metab North Am 1994; 23:893-922.

2. Behre HM, Baus S, Kliesch S, Keck C, Simoni M, Nieschlag E. Potential of testosterone buciclate for male contraception: endocrine differences between responders and nonresponders. J Clin Endocrinol Metab 1995;80:2394-403.

3. Handelsman DJ, Conway AJ, Boylan LM. Suppression of human spermatogenesis by testosterone implants. J Clin Endocrinol Metab 1992;75:1326-32.

4. Bagatell CJ, Bremner WJ. Androgens in men-uses and abuses. N Engl J Med 1996;334:707-14.

5. Coert A, Geelen J, de Visser J, Van der Vies. The pharmacology and metabolism of testoserone undecanoate (TU), a new orally active androgen. Acta Endocrinol 1975;79:789_ 800 .

6. Schurmeyer Th, Wickings EJ, Freischem W, Nieschlag E. Saliva and serum testosterone following oral testosterone undecanoate in normal and hypogonadal men. Acta Endocrinol $1983 ; 102: 456-62$.

7. Gooren LGJ. A ten-year safety study of the oral androgen testosterone undecanoate. J Androl 1994; 15:212-5.

8. Bebb RA, Anawalt BD, Christensen RB, Paulsen CA, Bremner WJ, Matsumoto AM. A promising male contraceptive approach: combined administration of testosterone and levonorgestrel. J Clin Endocrinol Metab 1996;81:757-62.

9. Meriggiola MC, Bremner WJ. Progestin-androgen combination regimens for male contraception. J Androl 1997;18:240-4.

10. Meriggiola MC, Bremner WJ, Paulsen CA, Valdiserri A, Costantino A, Pavani A, et al. Testosterone enanthate (TE) and low doses of cyproterone acetate (CPA) for contraception in men. [abstract OR58-7]. The International Congress of Endocrinology, San Francisco, June 14-15, 1996.

11. World Health Organization. WHO laboratory manual for the examination of human semen and sperm-cervical mucus interaction, 3rd ed. Cambridge: Cambridge University Press, 1992.

12. Berman NG, Wang C, Paulsen CA. Methodological issues in the analysis of human sperm concentration data. J Androl $1996 ; 17: 68-73$.

13. Meriggiola MC, Bremner WJ, Paulsen CA, Valdiserri A, Incorvaia $L$, Motta $R$, et al. A combined regimen of cyproterone acetate and testosterone enanthate as a potentially highly effective male contraceptive. J Clin Endocrinol Metab 1996; 81:3018-23. 
14. Kuriyama M, Wang MC, Papsidero LD, Killian CS, Shimano $\mathrm{T}$, Valenzuela LA, et al. Quantitation of prostatic specific antigen in serum by a sensitive enzyme immunoassay. Cancer Res 1980;40:4658-62.

15. Lohiya NK, Sharma OP, Sharma RC, Sharma RS. Reversible sterility by cyproterone acetate plus testosterone enanthate in langur monkey with maintenance of libido. Biomed Biochim Acta 1987;46(4):259-66.

16. Roy S. Experience in the development of hormonal contraceptive for the male. In: Asch RH editor. Recent advances in human reproduction. Rome: Fondazione per gli Studi sulla Riproduzione Umana, 1985;95-104.

17. Nieschlag E, Hoogen H, Bolk M, Schuster H. Clinical trial with testosterone undecanoate for male fertility control. Contraception 1978; 18:607-14.

18. Michel E, Bents H, Akhtar FB, Honigl W, Knuth UA, Sandow $\mathrm{J}$, et al. Failure of high dose sustained release luteinizing hormone releasing hormone agonist (Buserelin) plus oral testos- terone to suppress male fertility. Clin Endocrinol 1985;66375.

19. Behre HM, Oberpenning F, Nieschlag E. Comparative pharmacokinetics of androgen preparation: applications of computer analysis and simulation. In: Nieschalg E, Behre HM, editors. Testusterone, action, deficiency and substitution. Berlin: Springer-Verlag; 1990;115-35.

20. World Health Organization Task Force on Methods for the Regulation of Male Fertility Contraceptive. Efficacy of testosterone-induced azoospermia in normal men. Lancet 1990; 336:955-9.

21. World Health Organization Task Force on Methods for the Regulation of Male Fertility Contraceptive. Efficacy of testosterone-induced azoospermia and oligozoospermia in normal men. Fertil Steril 1996;65:821-9.

22. Parr JH, Seed M, Godsland I, Wynn V. The effects of reverse sequential anti-androgen therapy (cyproterone acetate and ethinylestradiol) on hematological parameters. J Endocrinol Invest $1987 ; 10: 237-9$. 